\title{
Immune related adverse events associated with anti-CTLA-4 antibodies: systematic review and meta-analysis
}

\author{
Anne Bertrand ${ }^{1{ }^{*}+}$, Marie Kostine ${ }^{1 \dagger}$, Thomas Barnetche ${ }^{1}$, Marie-Elise Truchetet ${ }^{1,2}$ and Thierry Schaeverbeke ${ }^{1,3}$
}

\begin{abstract}
Background: Targeting CTLA-4 is a recent strategic approach in cancer control: blocking CTLA-4 enhances an antitumor immunity by promoting T-cell activation and cytotoxic T-lymphocyte proliferation. This induction of a tolerance break against the tumor may be responsible for immune-related adverse events (irAEs). Our objective was to assess the incidence and nature of irAEs in oncologic patients receiving anti-CTLA-4 antibodies (ipilimumab and tremelimumab).
\end{abstract}

Methods: A systematic search of literature up to February 2014 was performed in MEDLINE, EMBASE, and Cochrane databases to identify relevant articles. Paired reviewers independently selected articles for inclusion and extracted data. Pooled incidence was calculated using $R^{\odot}$, package meta.

Results: Overall, 81 articles were included in the study, with a total of 1265 patients from 22 clinical trials included in the meta-analysis. Described irAEs consisted of skin lesions (rash, pruritus, and vitiligo), colitis, and less frequently hepatitis, hypophysitis, thyroiditis, and some rare events such as sarcoidosis, uveitis, Guillain-Barré syndrome, immune-mediated cytopenia and polymyalgia rheumatic/Horton. The overall incidence of all-grade irAEs was $72 \%$ (95\% Cl, 65-79\%). The overall incidence of high-grade irAEs was $24 \%(95 \% \mathrm{Cl}, 18-30 \%)$. The risk of developing irAEs was dependent of dosage, with incidence of all-grade irAEs being evaluated to $61 \%$ (95\% Cl, 56-66 \%) for ipilimumab 3 mg/kg and $79 \%$ (95 \% Cl, 69-89 \%) for ipilimumab 10 mg/kg. Death due to irAEs occurred in $0.86 \%$ of patients.

The median time of onset of irAEs was about 10 weeks (IQR, 6-12) after the onset of treatment, corresponding with the first three cycles but varied according to the organ system involved. Such immune activation could also be indicative for tumor-specific T-cell activation and irAE occurrence was associated with clinical response to CTLA-4 blocking in $60 \%$ of patients.

Conclusion: The price of potential long-term survival to metastatic tumors is an atypical immune toxicity, reflecting the mechanism of action of anti-CTLA-4 antibodies. A better knowledge of these irAEs and its management in a multidisciplinary approach will help to reduce morbidity and therapy interruptions.

Keywords: Anti-CTLA4 antibodies, Colitis, Dermatitis, Hypohysitis, Immune related adverse events, Ipilimumab, Metastatic tumors, Oncology, Tremelimumab

\footnotetext{
*Correspondence: anne.bertrand87@gmail.com

${ }^{\dagger}$ Equal contributors

'Département de Rhumatologie, Hôpital Pellegrin, CHU de Bordeaux,

Bordeaux, France

Full list of author information is available at the end of the article
} 


\section{Background}

Approval of the first cancer immunotherapies suggests a promising therapeutic approach in some metastatic cancers [1]. In contrast to most oncologic treatments, antibodies target lymphocyte receptors or their ligands (and not the tumor cells directly) in order to enhance endogenous anti-tumor activity. Among these receptors, cytotoxic T-lymphocyte-associated antigen-4 (CTLA-4) is a particularly important immune checkpoint receptor and the first to be clinically targeted in oncology.

The concept of immunosurveillance and involvement of the immune system in cancer development has been known for several years [2]. In the last two decades, efforts to activate anti-cancer host immunity were focused on T-cells due to their central role in the anti-cancer adaptive immune response, which is regulated by numerous co-stimulatory and inhibitory signals through tumor antigen recognition by the T-cell receptor. Thus, blockades of immune checkpoints with antagonists of inhibitory pathways have been developed and anti-CTLA-4 antibodies are precursors in this domain [3] (Mechanism of action: anti CTLA-4 antibodies in Fig. 1). CTLA-4, expressed exclusively on T-cells, acts as a negative costimulatory signal, inhibiting $\mathrm{T}$-cell activation and proliferation to maintain self-tolerance and protect from autoimmunity [4]. This role is supported by the lethal lympho-proliferation and autoimmunity in CTLA-4 knockout mice [5]. Recently, heterozygous germline mutations in CTLA-4 have been identified in four unrelated families with severe immune dysregulation [6]. Interestingly, these mutations show the spectrum of clinical immune complications that can be anticipated from anti-CTLA-4 drugs.
Thus, a fully humanized anti-CTLA-4 monoclonal antibody immunoglobulin (Ig) G1 isotype (ipilimumab) was approved by the Food and Drug Administration (FDA) in 2011 at a dosage of $3 \mathrm{mg} / \mathrm{kg}$ every 3 weeks for four cycles in advanced melanoma, with evidence of improved survival [7, 8]. An IgG2 isotype (tremelimumab) was developed at a dosage of $15 \mathrm{mg} / \mathrm{kg}$ every 90 days to minimize complement activation and reduce the risk of cytokine release syndrome [9]. The clinical value of antiCTLA-4 antibodies is being investigated in various cancer types including prostate, renal, bladder, colorectal, esophageal, pancreatic, gastric, hepatocellular, and pulmonary malignancies as well as mesothelioma and lymphoma [10].

As might be expected with blocking CTLA-4, the induction of a tolerance break against the tumor may be responsible for a variety of specific immune-related adverse events (irAEs) that occur in approximately $60 \%$ of the patients treated by ipilimumab [7]. These include skin, gastrointestinal, hepatic, endocrine, neurologic, hematologic, ophthalmologic, and rheumatologic autoimmune diseases.

Our objective was to assess the incidence and the nature of irAEs in oncologic treatment with anti-CTLA-4 antibodies (ipilimumab and tremelimumab) through a systematic review and meta-analysis of the literature.

\section{Methods}

\section{Data sources and searches}

A systematic literature search was performed up to February 2014 in the Medline, Embase, and Cochrane databases to identify relevant articles. Two investigators ( $\mathrm{AB}$ and $\mathrm{MK}$ ) together determined the optimal search strategy checking several combinations of keywords with

\section{A T-cell activation}

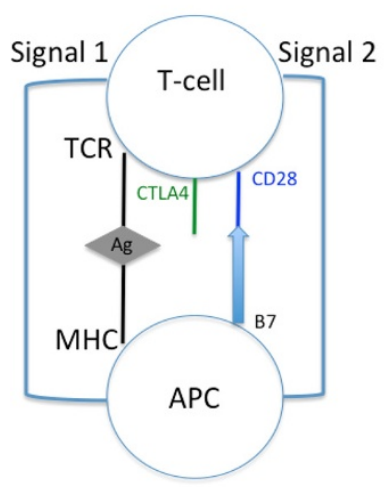

B T-cell downregulation

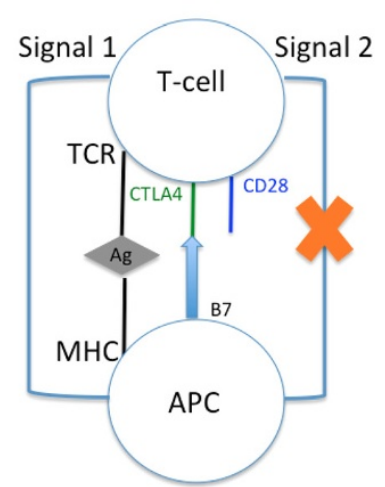

C Restoration of T-cell activation

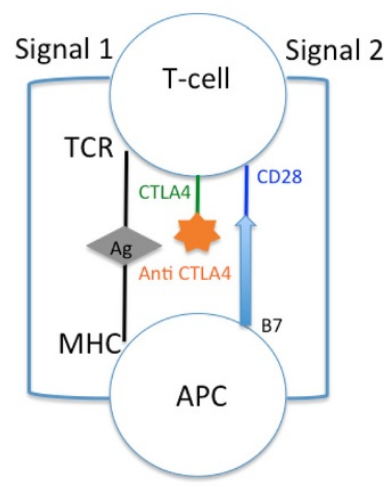

Fig. 1 Mechanism of action: CTLA-4 and anti-CTLA-4 antibodies. Two signals are required to initiate an immune response. For the first signal (signal 1), tumor associated antigen (Ag), is presented by major histocompatibility complex (MHC) on antigen presenting cell (APC) and recognized by the toll-like receptor (TCR) of T-cell. Signal 2 occurs in response to binding of CD80 or CD86 (B7) on APC cell with CD28 receptor on T-cell (a). CTLA-4 is a homolog of CD28 and limits proliferative response of activated T-cell competing with CD28 for ligand B7. This inhibition occurs in response to binding of CD80 or CD86 on APC with CTLA-4 receptor on T-cell and interrupts signal 2 (b). Anti-CTLA-4 antibodies blocks CTLA-4 and enhances T-cell activation and proliferation (c) 
the Boolean logical operators AND/OR. A consensus was reached and validated by all authors. Hence, the keywords used were "safety OR security OR side effects OR adverse events AND (anti CTLA4 OR anti CTLA-4 OR ipilimumab OR tremelimumab)" in Medline and Embase, and "anti CTLA4 OR anti CTLA-4 OR ipilimumab OR tremelimumab" in the Cochrane database. The search was limited to studies on human beings and published in English. Manual searches from bibliographic references were also performed after reading of the first selection of articles. Articles published as full text were preferable in order to study irAEs in detail and to check the quality assessment of trials included in the metaanalysis. Additionally, many medical specialties are concerned with these side effects due to their diversity and it would thus be difficult to check all conference meetings in 2 years prior to the study. Therefore, unpublished studies were not searched.

\section{Eligibility criteria and study selection}

We included clinical trials and case reports that reported irAEs in oncologic patients receiving anti-CTLA-4 antibodies (ipilimumab or tremelimumab). Patients included were adults with a diagnosis of metastatic cancer or unresectable tumor. They could have received previous oncologic therapy before inclusion. Patients with anti-CTLA-4 prescribed in combination with other treatments or patients with previous receipt of anti-CTLA- 4 antibodies were excluded. The two investigators conducted study selection and manual searches in bibliographic references independently, selecting the relevant articles initially on the basis of titles and abstracts, and then on the full texts.

\section{Outcomes}

Incidence evaluation was based on the number of irAEs for global and specific irAEs (skin, gastrointestinal, endocrine, and hepatic diseases) and their grade (1-5; recorded according to Version 2, 3 or 4 of the Common Terminology Criteria for Adverse Events of the National Cancer Institute). Grades $\geq 3$ were considered high-grade.

\section{Data extraction}

Each investigator performed the reading and data extraction independently. They used, for each study, a standard data extraction form and re-read together the articles in the event of any discrepancy in their interpretation. When data were not available, efforts were made to contact first authors.

Clinical trials were used to determine the incidence of irAEs. Information on the author and year of publication, population size, study design, treatment (ipilimumab or tremelimumab) and dosing regimen, duration of treatment (and number of infusions), and irAEs outcomes was extracted.
Case reports were used to describe the diversity of irAEs. Patient characteristics, the previous oncologic treatment, and the nature of each irAE, their onset, their treatment, and outcome were all recorded. Cancer outcome was also noted when reported in the article (partial or complete remission, stability, or progression).

\section{Quality assessment}

The Cochrane Collaboration's tool was used to assess risk of bias and to evaluate the quality of articles included in the meta-analysis [11], addressing sequence generation, allocation concealment, blinding of participants and personnel, incomplete outcome data, selective outcome reporting, and other sources of bias. Disagreements among investigators were discussed and agreement was reached by consensus.

\section{Data synthesis and analysis}

The primary objective of the study was the number of irAEs for each group of treatment (ipilimumab and tremelimumab). An incidence was estimated for each study included in the meta-analysis estimation. Statistical heterogeneity among the selected studies was tested based on the Q-test $\left(\chi^{2}\right)$, using a significant level of 0.05 , and reported with the $\mathrm{I}^{2}$ statistic in which high values indicate high heterogeneity. If heterogeneity was not rejected by the Q-test or under a threshold of $30 \%$, all meta-analyses were carried out using the inverse variance approach (fixed-effect model); otherwise, the inverse variance corrected by the inter-study variability was used (random-effect model). This method was not relevant for the question addressed herein due to the presence of zero values in adverse event incidences. In this case, a correction $(\lambda)$ was introduced in the variance calculation (classically adding 0.5 to the number of event counts), and the exact formula of variance became:

$$
\frac{(\operatorname{count}+\lambda)(n-\operatorname{count}+\lambda)}{(n+2 \lambda)^{3}}
$$

It provided a common weighted incidence estimate with $95 \%$ confidence interval (CI), taking into account the weight of the different samples. Incidences and their $95 \%$ CIs were shown on forest plots. Publication bias was assessed using the funnel plot method. All computations were performed using $\mathrm{R}$ software $(\mathrm{R}$ version 2.12.2 (2012-10-26) with the package Meta and the function Metaprop.

\section{Results}

Literature search

The literature search identified 491 articles in databases and manual searches retrieved five additional articles. Among these 496 articles, 373 were excluded after 
reading of the abstracts due to duplicate articles, oncologic treatment in combination with other drugs, review articles, or basic research. Finally, 123 articles were fully reviewed and 81 were considered relevant for the present study: 24 clinical trials and 57 case reports (Fig. 2).

Clinical trials in which patients were treated according to the labeling of the products (ipilimumab $3 \mathrm{mg} / \mathrm{kg}$ every 3 weeks for at least four cycles and tremelimumab at $15 \mathrm{mg} / \mathrm{kg}$ every 90 days) or at upper dosage were included for meta-analysis. As one study was retrospective and one used ipilimumab for only one or two doses, these two studies were only selected in the systematic review but not for meta-analysis [12, 13].

\section{Incidence of irAEs - data from clinical trials General characteristics}

In total, 1265 patients from 22 clinical trials were included for meta-analysis to assess the incidence of irAEs with anti-CTLA-4 treatment (Table 1) [7, 14-34]; 18 studies concerned ipilimumab treatment and four concerned tremelimumab, but incidence data of global irAEs for tremelimumab was available in only one study [31]. Moreover, the tremelimumab phase III randomized clinical trial in advanced melanoma was not included because 46 patients (14 \%) received ipilimumab in the control arm [35]. Most of the studies were not blind (18/22). Single arm studies were retrieved in 11 articles, six studies were randomized and five were not. Half of the studies were monocentric.
Anti-CTLA-4 antibodies were mainly given for melanomas. Other studies concerned renal cell carcinoma, mesothelioma and pancreatic, gastric, esophageal, colorectal, prostatic, and bladder cancer. The median duration of follow-up in these clinical trials was 23 months (IQR, 19-32). It is noteworthy to consider that, in 20 studies (90\%), patients with pre-existing autoimmune disease were not eligible for inclusion.

\section{Global incidence of irAEs}

The overall incidence level of irAEs reported with antiCTLA-4 treatment was $72 \%$ (95\% CI, 65-79; I $\left.{ }^{2}, 81.94\right)$ for all-grade and $24 \%$ (95\% CI, 18-30; $\mathrm{I}^{2}, 79.97$ ) for high-grade (Fig. 3a,b).

The incidence of all-grade irAEs varied according to the dosage of the drug, from $61 \%$ (95\% CI, 56-66; $\mathrm{I}^{2}$, 0 ) in patients receiving ipilimumab at $3 \mathrm{mg} / \mathrm{kg}$ to $79 \%$ (95\% CI, 69-89; $\left.\mathrm{I}^{2}, 85\right)$ in patients treated with ipilimumab $10 \mathrm{mg} / \mathrm{kg}$. This dose effect was corroborated in high-grade irAEs, evaluated to $17 \%$ (95\% CI, 10-23; $\mathrm{I}^{2}$, $71,85)$ with ipilimumab $3 \mathrm{mg} / \mathrm{kg}$ and $31 \%$ (95\% CI, 22-39; $\mathrm{I}^{2}$, 62) with ipilimumab $10 \mathrm{mg} / \mathrm{kg}$ (Figures S5, S6 and S7 in Additional file 1). To perform a statistical comparison between the two main doses $(3 \mathrm{mg} / \mathrm{kg}$ and $10 \mathrm{mg} / \mathrm{kg}$ ) we made a subgroup analysis within the three studies comparing the two doses $[17,19,30]$. The risk ratio (RR) of developing an irAE with ipilimumab at 10 $\mathrm{mg} / \mathrm{kg}$ compared with $3 \mathrm{mg} / \mathrm{kg}$ was 3.10 (1.59-6.03;

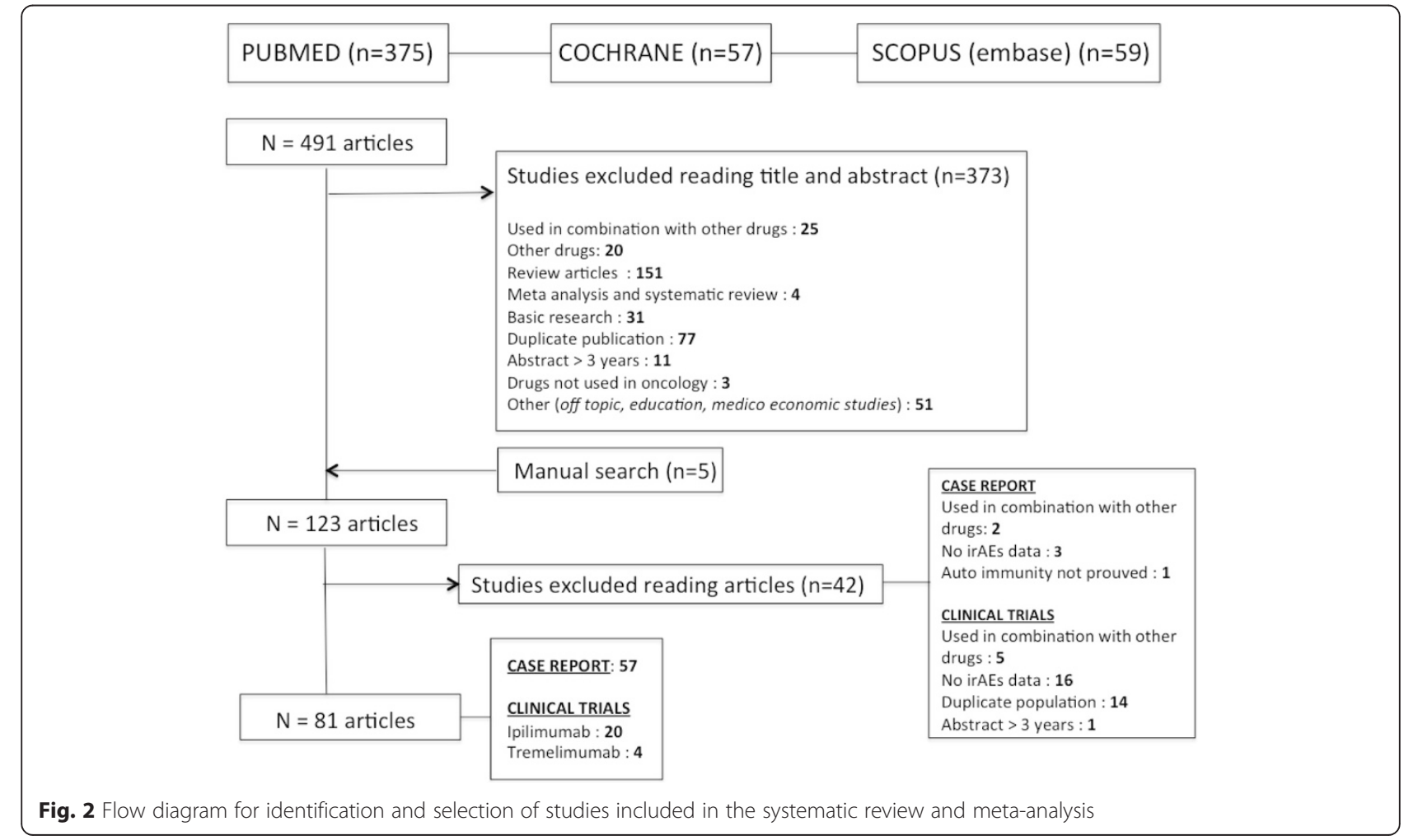


Table 1 Characteristics of studies included for meta-analysis

\begin{tabular}{|c|c|c|c|c|c|c|}
\hline Trial & Design & Cancer & Enrollment size & Anti-CTLA-4 & Dose $(\mathrm{mg} / \mathrm{kg})$ & CTC for AE version \\
\hline Hodi [7] & RCT, phase III & Melanoma & 676 & Ipilimumab & 3 & 3 \\
\hline Wilgenhof [14] & Prospective observational study & Melanoma & 50 & Ipilimumab & 3 & 4 \\
\hline Delyon [15] & Prospective observational study & Melanoma & 96 & Ipilimumab & 3 & 4 \\
\hline Margolin [16] & Open label, phase II & Melanoma & 72 & Ipilimumab & 10 & 3 \\
\hline Hamid [17] & $\begin{array}{l}\text { Randomized, double blind, } \\
\text { phase II }\end{array}$ & Melanoma & 82 & Ipilimumab & $3 ; 10$ & $\mathrm{n} / \mathrm{a}$ \\
\hline Danielli [18] & Single arm, phase II & Melanoma & 13 & Ipilimumab & 10 & 3 \\
\hline Wolchok [19] & $\begin{array}{l}\text { Randomised phase II, } \\
\text { dose ranging study }\end{array}$ & Melanoma & 217 & Ipilimumab & $0.3 ; 3 ; 10$ & 3 \\
\hline O’Day [20] & Multicenter, single arm, phase II & Melanoma & 155 & Ipilimumab & 10 & 3 \\
\hline Hersh [21] & RCT, phase ॥ & Melanoma & 74 & Ipilimumab & 3 & 2 \\
\hline Weber [22] & $\begin{array}{l}\text { Randomized, double blind, } \\
\text { phase II }\end{array}$ & Melanoma & 115 & Ipilimumab & 10 & 3 \\
\hline Yang [23] & $\begin{array}{l}\text { Randomized, double blind, } \\
\text { phase II, dose ranging study }\end{array}$ & Renal cell & 61 & Ipilimumab & $1 ; 3$ & $\mathrm{n} / \mathrm{a}$ \\
\hline Downey [24] & Multicenter, single arm, phase II & Melanoma & 139 & Ipilimumab & 9 & $\mathrm{n} / \mathrm{a}$ \\
\hline Ku [25] & Compassionate use trial & Melanoma & 53 & Ipilimumab & 10 & 3 \\
\hline Di Giacomo [26] & Single arm, phase II & Melanoma & 27 & Ipilimumab & 10 & 3 \\
\hline Royal [27] & Single arm, phase II & Pancreatic & 27 & Ipilimumab & 3 & 3 \\
\hline Le DT [28] & $\begin{array}{l}\text { Randomized, open label, } \\
\text { phase IB }\end{array}$ & Pancreatic & 30 & Ipilimumab & 10 & 3 \\
\hline Weber [29] & Phase I/II & Melanoma & 88 & Ipilimumab & $\mathrm{n} / \mathrm{a}$ & $\mathrm{n} / \mathrm{a}$ \\
\hline Slovin [30] & $\begin{array}{l}\text { Non randomized, open label, } \\
\text { multicenter, phase I/II }\end{array}$ & Prostate & 71 & Ipilimumab & $3 ; 5 ; 10$ & 3 \\
\hline Calabro [31] & Open label, single arm, phase ॥ & Mesothelioma & 29 & Tremelimumab & 15 & 3 \\
\hline Chung [32] & Multicenter, single arm, phase II & Colorectal & 47 & Tremelimumab & 15 & 3 \\
\hline Ralph [33] & Single arm, phase II & Gastric and esophageal & 18 & Tremelimumab & 15 & 2 \\
\hline Ribas [34] & Phase I & Melanoma, renal cell, colon & 39 & Tremelimumab & $10 ; 15$ & 2 \\
\hline
\end{tabular}

CTC for AE version, Common Terminology Criteria for Adverse Events version; RCT, Research clinical trial; n/a, Non-available

$P=0.0008)$ for the overall incidence level of irAEs for high grade. RR of overall incidence level of irAEs for all grade did not reach a statistically significant difference (RR, 1.16 (0.97-1.38); $P=0.10$; Fig. 4a,b).

\section{Incidence of organ-specific irAEs}

The skin and the gastrointestinal tract were mostly affected, in $44 \%(95 \% \mathrm{CI}, 38-49.5)$ and $35 \%(95 \% \mathrm{CI}$, 29-41) of cases, respectively, while endocrine and hepatic organs were less affected, in $6 \%(95 \% \mathrm{CI}, 4-8)$ and $5 \%$ (95\% CI, 2-7), respectively. Other events, such as neurologic, hematologic, ophthalmologic, or rheumatologic diseases, were rare.

Almost all skin, endocrine, and hepatic irAEs were low grade (less than $5 \%$ ); high-grade irAEs remained more frequent in gastrointestinal events at $11 \%(95 \% \mathrm{CI}, 8-13.5$; Fig. 3c and Figure S8 to Figure S27 in Additional file 1).

As global irAEs, organ-specific irAEs seemed to be more important for patients treated with ipilimumab at
$10 \mathrm{mg} / \mathrm{kg}$ except for high-grade endocrine irAEs (Fig. 3c). However, in the subgroup analysis $[17,19,30]$, a statistically significant difference was only found between the two doses for all grade gastrointestinal irAEs with a RR of $1.43(1.04-1.96 ; P=0.03$; Figures $\mathrm{S} 28$ to $\mathrm{S} 31$ in Additional file 1).

There appeared to be fewer irAEs with tremelimumab, except those concerning hepatic disease.

\section{Incidence of death related to irAEs}

Death due to irAEs occurred in 11 patients $(0.86 \%)$, often related to colic bowel perforation for patients with colitis.

\section{Nature of irAEs - data from case reports and retrospective studies \\ General characteristics}

In addition to retrospective studies and some descriptive clinical trials, our research identified 100 patients from 


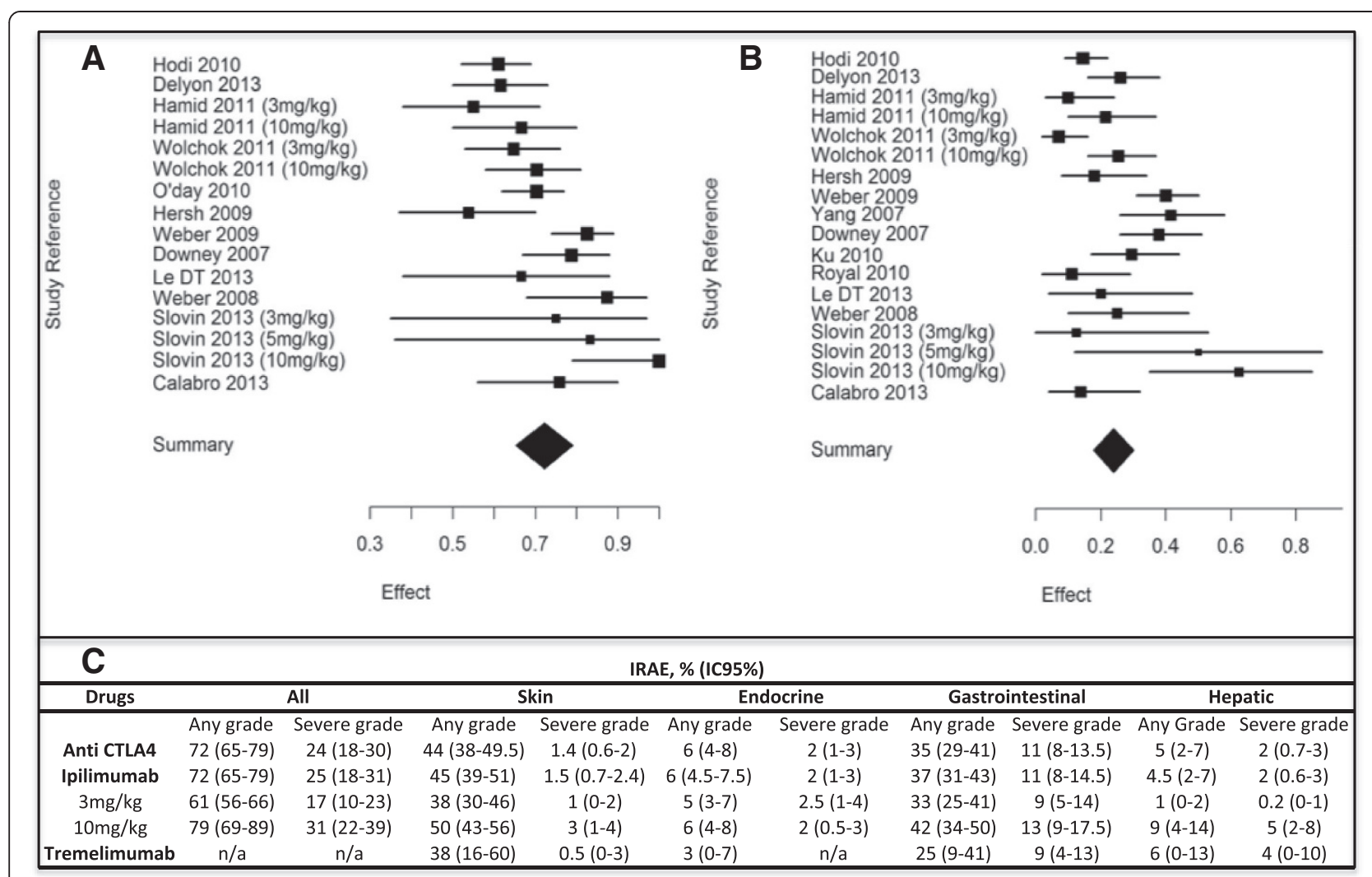

Fig. 3 Incidence of global immune-related adverse events (irAEs) with anti-CTLA-4, all-grade (a) and severe grade (b). For ipilimumab treatment, different dosages were used: $3 \mathrm{mg} / \mathrm{kg}, 10 \mathrm{mg} / \mathrm{kg}$, and $15 \mathrm{mg} / \mathrm{kg}$. Only one study [31] reported global irAEs with tremelimumab treatment, at 15 $\mathrm{mg} / \mathrm{kg}$ dosage. IrAEs associated with anti-CTAL-4 antibodies (c)

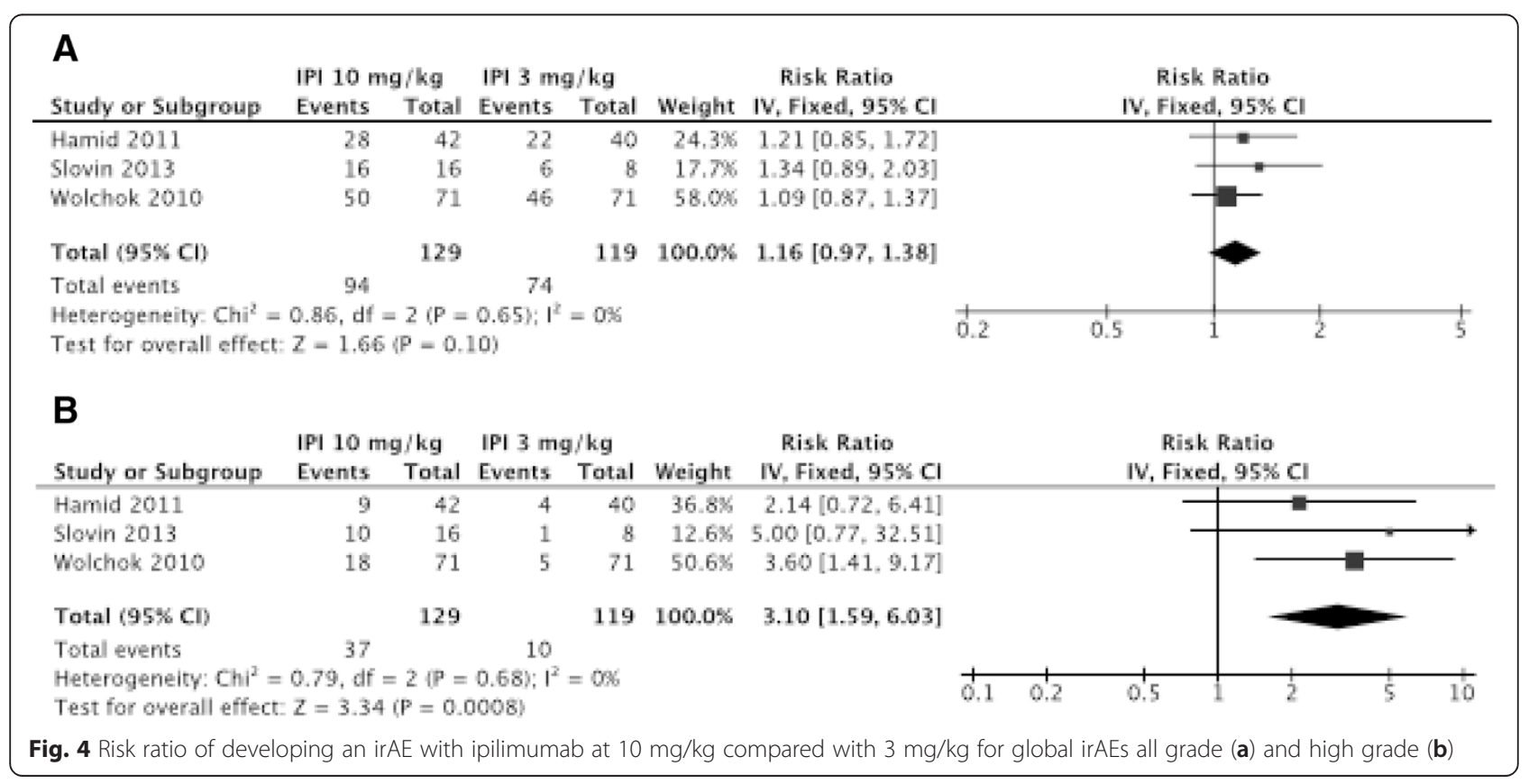


57 case reports with at least one irAE [26, 36-91]. Among them, 18 presented several irAEs. The general characteristics of these patients are summarized in Additional file 1: Table S2. Anti-CTLA-4 treatments were mainly used in melanoma (94\%). Ninety-nine patients received ipilimumab and one patient received tremelimumab; 48 patients (48\%) had failed at least one previous oncologic therapy before receiving anti-CTLA4 antibodies. The irAEs occurred in a median of 10 weeks (IQR, 6-12), within the first three cycles of ipilimumab treatment.

Interestingly, clinical remission (partial or complete), or at least cancer stabilization, was noted for $60 \%$ of patients who experienced an irAE. When irAEs were diagnosed, anti-CTLA-4 was stopped in $76.2 \%$ of patients.

\section{Nature of irAEs}

Cutaneous irAEs were by far the most common immune side effect of anti-CTLA-4 treatment and occurred within the first month of treatment. Pink red papules coalescing into thin plaques associated with mild to severe pruritus were usually described. A Koebner phenomenon was sometimes associated. This dermatitis was usually well tolerated and limited. It was mainly localized at proximal extensor surfaces of the limbs, trunk, and distal extremities. Palms and soles were often spared and head involvement was rare [92].

Histologically, an epidermal spongiosis and a superficial perivascular CD4 predominant T-cell infiltrate were present. An increased tissue (in papillary dermis) and peripheral blood eosinophil levels were described [93]. Treatment consisted of topical corticosteroids. Severe grades were treated with oral corticosteroids (starting at $1 \mathrm{mg} / \mathrm{kg}$ ) and discontinuation of anti-CTLA-4 treatment.

Exacerbation of pre-existing dermatitis as eczema, vitiligo, or rosacea and extensive alopecia were also reported [36, 37, 92]. Moreover, a case of Sweet's syndrome was reported in a patient undergoing ipilimumab therapy for metastatic melanoma [38]. After the second infusion, she developed fever and cutaneous eruption on her hands. Punch biopsy confirmed neutrophilic dermatitis and symptoms improved with corticosteroids therapy.

Endocrine irAEs were part of this spectrum of specific irAEs reported to anti-CTA-4 antibodies (Additional file 1: Table S3). They occurred within an average of 11 weeks but were not dose dependent, unlike other irAEs.

Autoimmune hypophysitis was the most frequent endocrine side effect, reported in up to $13 \%$ of clinical trials. It was similar to lymphocytic hypophysitis, sharing the same clinical, biological, and radiological features [94]; 33 cases were reported. Symptoms were related to the anterior hypopituitarism (hormonal deficiencies) and pituitary mass effect [39]. Most patients presented headache (51.8 \%: 14/27 patients), asthenia (59.3\%: 16/27), erectile dysfunction, and decreased libido. Visual disturbances were rare, reported only in one patient [40]. Indeed, mass syndrome was usually moderate: 3.4-6 $\mathrm{mm}$ in pre-treatment and 7.7-11.8 $\mathrm{mm}$ after ipilimumab therapy [39]. Affected areas were mainly the hypothalamic-pituitary-adrenal axis (92.9\%; $26 / 28$ patients) and the thyrotropin axis (89.3\%; 25/28), followed by the gonadal axis $(71.4 \%$; 20/28). The lactotrope and somatotropic axes were less frequently involved (21.4 \% (6/28) and $10.7 \%(3 / 28)$, respectively). One case of hypernatremia secondary to syndrome of inappropriate antidiuretic hormone and one case of diabetes insipidus were associated with ipilimumabinduced hypophysitis [41, 42]. MRI aided in the diagnosis of hypophysitis by identifying enlargements of the pituitary gland $(68.2 \% ; 15 / 22)$ and homogeneous enhancements after injection of gadolinium (31.8\%; $7 / 22$ ); MRI could be normal (6/22), without excluding the diagnosis. Treatment consisted of hormone substitution and high-dose oral corticosteroids with a median dose of $80 \mathrm{mg}$ prednisone equivalent (IQR, 60-106), decreasing over 1 month and backed by hydrocortisone. MRIs normalized with corticosteroids in six patients. However, hormonal deficits persisted in $75 \%(15 / 20)$ and required long-term hormonal replacement, especially corticosteroids. Five cases reported complete healing.

Hypo- and hyperthyroidism secondary to thyroiditis were rare, up to $5.6 \%$ in clinical trials. One case reported bilateral Graves' ophtalmopathy with high thyroperoxydase and thyroglobulin antibodies after two cycles of ipilimumab therapy [43].

Gastrointestinal irAEs were important and potentially severe immune complications reported with CTLA-4 blocking drugs (Additional file 1: Table S3). Patients received an average of three infusions (IQR, 2-4) before the onset of symptoms.

Colitis was reported in 21 patients. Clinical manifestations were diarrhea $(95.2 \% ; 20 / 21)$, abdominal pain (38.1 $\% ; 8 / 21)$, rectal blood $(23.8 \% ; 5 / 21)$, and nausea, with or without fever. Colitis could be life threatening with fatal colic bowel perforation, reported in two patients [54].

Colonoscopy could be normal or reveal variable abnormalities, including edema, erythema, ulcers, friability, exudate, erosions, or bleeding [55].

Histology showed ulcerative epithelial defect (35.3\%; $6 / 17)$, lymphocytic $(64.7 \%$; 11/17) or neutrophilic infiltrates $(52.9 \%$; 9/17), or both $(35.3 \%$; 6/17), and sometimes with eosinophil cells. Crypt micro-abscesses and architectural distortion were also occasionally seen [55]. Histopathology shared some features with inflammatory bowel disease and graft versus host disease. Colitis management is proposed in analogy with the treatment of these two pathologies [95]. 
Treatment consisted of symptomatic drugs (loperamide) and rehydration for grade 1 irAEs. For grade 2, antiCTLA-4 discontinuation and moderate dose of oral steroids or budesonide are recommended. For severe grades, a high dose of steroids (sometimes intravenous) was recommended as first line treatment. In case reports, the median dose was $156 \mathrm{mg}$ prednisone equivalent (IQR, 150-225) and in the event of no improvement in 1 week, infliximab (one or two infusions at $5 \mathrm{mg} / \mathrm{kg}$ ) was proposed. For refractory colitis, a colectomy had to be performed [57]. Healing was reported in $91.5 \%$ of patients.

Hepatitis was described in up to $19 \%$ of clinical trials. Patients presented elevated alanine aminotransferase and aspartate aminotransferase, with or without hyperbilirubinemia, usually in the absence of clinical symptoms [63]. Biopsies from patients experiencing acute immune-related hepatotoxicity showed T-cell infiltrates (87.5 \%; 7/8). Most patients responded to corticosteroids but several cases needed immunosuppressive therapies such as tacrolimus, mycophenolate, or antithymocyte globulin therapy [63, 64].

One case illustrated ipilimumab-related pancreatitis considered to be immune-related due to detection of anti-pancreas antibodies [66].

A case of coeliac disease was also reported [67]. Biology revealed anti-tissue transglutaminase and anti-gliadine antibodies. The duodenal biopsies showed a malabsorptive pattern; a gluten-free diet helped to stop diarrhea.

\section{Other irAEs}

Various neurologic irAEs, such as Guillain-Barré syndrome [42, 68, 69], transverse myelitis [70], aseptic meningitis [42], inflammatory myopathy [71], orbital myositis [72], or myasthenia [70], were described (Additional file 1: Table S3). Despite adapted treatments (steroids, immunoglobulin therapy, and plamapheresis), authors reported three deaths and five patients with long-lasting neurologic irAEs related to anti-CTLA-4.

Additionally, six cases of sarcoidosis were reported [77-82]. Symptoms occurred in the first four cycles (IQR, 3-5) corresponding within the first 15 weeks (IQR, 12-24). Dyspnea (50 \%; 3/6) and skin lesions (50\%; $3 / 6)$ were usually described. Computed tomography showed mediastinal lymph nodes in $83.3 \%(5 / 6)$ of cases and micronodular and reticulonodular lesions in $80 \%$ (4/ 6). Diagnosis was confirmed by biopsies (bronchial or cutaneous) revealing granulomas in all $(5 / 5)$ cases. Healing was reported in all cases with oral steroids treatment at a dosage of $75 \mathrm{mg}$ prednisone equivalent (IQR, 50-100).

Many other events were also reported with anti-CTLA4 antibodies, including uveitis [83], organizing pneumonia [84], lupus nephritis [85], autoimmune cytopenia [85-87], and hemophilia A [89], as well as a recently published case of polymyalgia/giant cell arteritis [90].

\section{Quality assessment}

Most of the studies were not blind or single-arm since the majority were compassionate trials. Thus, since investigators were aware of which treatment patients had received and of the possible drug side effects, it is possible that irAEs were over-reported. Despite these elements, most information was retrieved from trials with a moderate risk of bias. Further details regarding the quality assessment are available in Additional file 1: Table S4. No significant publication bias was found for all meta-analysis.

\section{Discussion}

To our knowledge, this is the first systematic review and meta-analysis reporting overall published irAEs related to anti-CTLA-4. From 22 clinical trials included in the pooled analysis, we found a respective incidence of $72 \%$ (95\% CI, 65-79; $\mathrm{I}^{2}, 81.94$ ) for all-grade irAEs and $24 \%$ (95\% CI, 18-30; $\mathrm{I}^{2}$, 79.97) for high-grade irAEs leading to hospitalization or intravenous treatment. These results highlight the high risk of irAEs with anti-CTLA-4 drugs in patients with such metastatic cancers. These values were found to be quite similar to those of a retrospective review of safety data including 1498 patients treated with ipilimumab at various doses on 14 completed phase I-III trials [96], reporting inflammation drug-related adverse events in $64 \%$, with $18 \%$ being of severe grades.

Among the wide spectrum of irAEs, cutaneous reactions and gastrointestinal tract immune side effects were commonly encountered, followed by endocrinopathies and hepatitis. However, several reports included nervous system disorders, sarcoidosis, respiratory, renal, or other organ immune involvement. Indeed, physicians of various specialties should be concerned by these irAEs and must examine all symptoms as being potentially induced by anti-CTLA-4 treatment. Voskens et al. [97] summarized and described, by organ system, the rare ipilimumabinduced immune side effects among 19 skin cancer centers. Through this complete description of previously unreported irAEs, several specialized centers shared their experience of irAEs in order to increase awareness and introduce an earlier management of potentially severe side effects. Recently, Teply et al. [98] also provided identification, description, and management of toxicities from immune checkpoint-blocking drugs (CTLA-4, PD-1, and PD-L1 antibodies).

An important clinical point is the early onset of irAEs, in general within the first 10 weeks, corresponding to a mean of three cycles for ipilimumab treatment, but varies according to the organ system involved. McDermott et al. [99] reported the occurrence of new ipilimumabrelated immune toxicity in 7 of 78 patients with 2 years' survival after ipilimumab treatment. These irAEs were mostly low grade and occurred more than 70 days after 
the last dose of ipilimumab. Three studies provide additional information on the safety profile of ipilimumab retreatment, comparable with that observed during ipilimumab induction and without new types of toxicity [100-102]. Lebbé et al. [100] observed a lower incidence of irAEs among patients retreated with ipilimumab 10 $\mathrm{mg} / \mathrm{kg}$ who were previously treated with ipilimumab 3 $\mathrm{mg} / \mathrm{kg}(67.6 \%)$ and $10 \mathrm{mg} / \mathrm{kg}(56.6 \%)$ compared with patients who received ipilimumab $0.3 \mathrm{mg} / \mathrm{kg}$ (75\%); this was also reported by Chiarion-Sileni et al. [101] in the Italian expanded program. They suggested the possibility of a dose-dependent CTLA-4 binding in caution with the selection bias since patients with high-grade irAEs in the parent study would not have been eligible for retreatment.

Few data are published on the long-term follow-up of anti-CTLA-4-induced irAEs. Indeed, anti-CTLA-4 antibodies are a recent approach in oncology and the follow-up in clinical trials is currently too short to assess long-term evolution of these side effects. Based on case reports, $91.5 \%$ of patients experiencing a gastrointestinal (colitis) irAE and $100 \%$ of patients with sarcoidosis recovered completely of their irAEs. However, patients with endocrine side effects (hypophysitis) were reported as healed in only $25 \%$ of cases. This data is relevant with a recent study following up anti-CTLA-4-induced hypophysitis for over 2.5 years and reporting a longterm hormonal replacement requirement in $86.6 \%$ of patients [103]. Indeed, the clinical features, management, and evolution of irAEs seem to be similar to known autoimmune diseases. These similarities beg the following questions: Do patients developing irAEs have particular genetic risk factors (e.g. HLA-DR alleles) such as those in autoimmune diseases? Could the CTLA-4 blockade be the trigger of long-term auto-immunity? Further studies are needed to provide these answers.

The overall incidence of irAEs observed with the two main doses of ipilimumab (3 mg/kg and $10 \mathrm{mg} / \mathrm{kg}$ ) seem to be significantly different and have a dose-dependent effect since the CIs of means did not overlap. The subgroup analysis confirmed this hypothesis, with a RR at 3.10 (1.59-6.03; $P=0.0008)$ of developing irAEs with a higher dosage $(10 \mathrm{mg} / \mathrm{kg})$ for high-grade global irAEs. It seems that treatment with tremelimumab has less irAEs, but the mechanism remains unclear. Patients receiving a lower dosage of FDA-approved therapy were not included in this meta-analysis, but it is noteworthy that there were very few irAEs for these sub-therapeutic doses [13].

Efficacy is also reported as having a dose-dependent effect [19]. A major question is the existence of a relationship between oncologic response and occurrence of irAEs, which could be indicative of tumor-specific T-cell activation. The present study has not been established to answer this question. However, based on case reports,
irAE occurrence seems to be associated with clinical response to CTLA-4 blocking: $60 \%$ of the patients presenting with irAEs experienced clinical remission (partial or complete) or at least cancer stabilization. Interestingly, several studies have also reported a strong correlation between clinical response to anti-CTLA-4 therapy and irAEs [23, 24, 95, 104, 105]. Thus, objective tumor response rates were around $30 \%$ in patients who developed autoimmune events, while $0-10 \%$ of the other patients responded to treatment. In a study by Downey et al. [24], all complete responders experienced high-grade irAEs. These observations corroborate the idea of a coupling autoimmunity and tumor immunity.

Under normal physiological conditions, CTLA- 4 acts as a negative T-cell co-stimulatory signal, maintaining the peripheral T-cell homeostasis and tolerance to self or environmental antigens [106]. Expression on activated conventional $\mathrm{T}$-cells is induced after $\mathrm{T}$-cell receptor signaling (Fig. 1) while it is constitutively expressed on T-regulator cells (CD4+FoxP3+). CTLA-4 is now established as a critical regulator of $\mathrm{T}$-regulator homeostasis and function [107]. Thus, if the CTLA-4 blockade enhances the intratumoral T-effector/T-regulator cell ratio in cancer patients, by depleting T-regulator cells [108], immunotherapy modulating CTLA-4 (such as abatacept) improves the regulatory T-cell inhibitory function in rheumatoid arthritis patients [109]. This example highlights the opposite therapeutic strategy between cancer patients and those affected by inflammatory/autoimmune diseases. Furthermore, T-regulator cell differentiation in the gut by commensal bacteria is known to actively engender mucosal tolerance. The frequency of colitis in patients receiving CTLA-4 blockade could be explained, in part, by the Tregulator depletion induced by this treatment [110].

Thus, given the critical role of CTLA-4 in immunologic homeostasis and the known irAE profile, patients with underlying autoimmune disease were usually excluded from clinical trials involving CTLA-4 blocking drugs. Few reports have been published concerning patients treated with ipilimumab despite an active autoimmune disease as rheumatoid arthritis, multiple sclerosis, ulcerative colitis, or Behçet's disease $[111,112]$. In three patients who presented rheumatoid arthritis, ulcerative colitis, and Behçet's disease, no aggravation of the immune disorder was noted and their cancer benefitted from the treatment. Although anecdotal, these descriptions raise the question of the current exclusion of anti-CTLA-4 treatment in patients with autoimmune disease, given the poor prognosis of a metastatic cancer. Furthermore, Lipson et al. [113] reported two successful administrations of ipilimumab to patients receiving an immunosuppressive regimen for kidney transplantation. It illustrates that ipilimumab could be a safe and effective option for solid organ transplantation in patients with a higher risk of melanoma. 
The management of immune toxicities has been welldeveloped by the manufacturer by working with the FDA to edit and diffuse irAE management guidelines [114]. In parallel, experts detailed and considered the management of irAEs by organ system $[98,115,116]$. Patients usually required high-doses of corticosteroids according to the irAE type and grade. Of note, a prophylactic strategy with budesonide to prevent ipilimumabinduced colitis was ineffective, with a similar rate of diarrhea/colitis for patients receiving budesonide and those receiving placebo [22]. Another important clinical finding is the lack of evidence that steroid administration affects oncologic response [95, 104]; immunosuppressive agents were used in the event of no early improvement (e.g. infliximab in colitis).

Ongoing research focuses on the identification of predictive biomarkers of treatment response and of irAE occurrence. A limited proportion of patients receiving CTLA-4-blocking drugs achieve the objective tumor response, while most have irAEs. Individual data from these long-term survivors will help identify genetic and/ or immunological biomarkers in order to define patient subsets likely to benefit from immunotherapy with adequate immune monitoring. Preliminary studies have investigated the genetic variation in CTLA-4; some variants seem to influence the response to therapy with improved overall survival and no occurrence of irAEs [117, 118]. Snyder et al. [119] also defined a genetic basis for benefit from CTLA-4 blockade in melanoma by whole-exome sequencing on tumors and matched blood samples. They identified a neo-antigen landscape specifically present in tumors with a strong response to CTLA-4. Regarding immunological parameters, a significant increase in T-cell ICOS expression (costimulatory molecule, third member of the CD28/CTLA-4 family) following ipilimumab treatment was found in melanoma patients who experienced disease control [120]. Recently, Vudattu et al. [121] described a reconstituted "humanized" mice model of human autoimmune disease in vivo that may provide insights into anti-CTLA-4 antibody effects on autoimmunity. These "humanized" mice treated with anti-CTLA-4 antibodies develop hepatitis, adrenalitis, and sialitis, as well as anti-nuclear antibodies (IgM or IgG). Thus, this model could be relevant to describe the irAEs observed in humans treated with anti-CTLA-4 antibodies and explore the immunologic pathways of these side effects [121].

Our study has some limitations. First, the diagnosis of irAEs may vary among investigators as definitions of irAEs in clinical trials are unclear. In Hodi et al. [7], an irAE was defined as an adverse event that was associated with exposure to the study drug and that was consistent with an immune phenomenon. For example, a rash could be a dermatologic irAE or an allergic reaction, and unfortunately we do not know if all patients with a rash were given a biopsy. This may lead to an overestimation of the incidence of irAEs associated with anti-CTLA-4. However, when the immune characteristic of the drugrelated adverse event was not specified, we did not record it. It would have been better to present results with an odds ratio to evaluate a risk, but this was not possible because most oncologic studies are single arm or compared with a chemotherapy gold standard, not a placebo. We selected patients receiving anti-CTLA-4 antibodies alone, and not in combination treatment, in order to estimate the real incidence of irAEs induced by these molecules. Most studies and reports concerned ipilimumab treatment due to the marketing authorization in advanced melanoma and future data concerning tremelimumab and other immunotherapies will be interesting. Finally, high level of heterogeneity was observed in this meta-analysis (around $80 \%$ for the majority of calculations). This heterogeneity was taken into account by performing random effects models, and its principal source was certainly the heterogeneity of the studies analyzed (differences in patient's profiles, various dosages of treatments, etc.).

Given the "up-to-date" subject and the emergence of cancer immunotherapy, increasing reports of antiCTLA-4-induced irAEs are published. Indeed, since our deadline of literature search, various auto-immune hematological [122, 123], renal [124], cutaneous [125-128], ophthalmologic [129-132], neurologic [133, 134], endocrine [132, 135-137], gastrointestinal [138, 139], and a central nervous system sarcoidosis [140] cases have been described.

\section{Conclusion}

The potential price of a long-term cure of metastatic tumors is atypical immune toxicity, reflecting the immune mechanism of action of anti-CTLA- 4 antibodies. A better knowledge of these irAEs and their management in a multidisciplinary approach will help to reduce morbidity and to guide therapy interruptions. Further studies are required to identify specific patient characteristics and/or biomarkers that may be associated with ipilimumab clinical efficacy in patients who did and did not develop an irAE.

\section{Additional file}

\footnotetext{
Additional file 1: Figures S5 to S7 Global immune-related adverse events (irAEs) with ipilimumab all dosage, $3 \mathrm{mg} / \mathrm{kg}$, and $10 \mathrm{mg} / \mathrm{kg}$ for all grades and high grade. Figures S8 to S27 Organ-specific irAES (endocrine, skin, gastrointestinal, and hepatic) for ipilimumab all dosage, $3 \mathrm{mg} / \mathrm{kg}$, and $10 \mathrm{mg} / \mathrm{kg}$ and Tremelimumab, for all grades and high grade. Figures S28 to S31 Risk ratio of developing irAEs with ipilimumab at $10 \mathrm{mg} / \mathrm{kg}$ comparing with $3 \mathrm{mg} / \mathrm{kg}$ for organ-specific irAEs (gastrointestinal, skin, endocrine, and hepatic). Table S2 General characteristics of patients receiving anti-CTLA4 antibodies described in case reports. Table S3 Organ-specific irAEs. Table S4 Quality assessment. (DOCX 12329 kb)
} 


\section{Abbreviations}

CTLA-4: Cytotoxic T-lymphocyte-associated antigen-4; FDA: Food and Drug Administration; irAEs: Immune-related adverse events.

\section{Competing interests}

The authors declare that they have no competing interests.

\section{Authors' contributions}

All authors were involved in drafting the article or revising it critically for important intellectual content. All authors approved the final version to be published. All authors agreed to be accountable for all aspects of the work in ensuring that questions related to the accuracy or integrity of any part of the work were appropriately investigated and resolved. Study conception and design: TS, AB, MK, TB and MET. Acquisition of data: $A B$ and MK. Analysis and interpretation of data: TS, AB, MK, TB and MET. No copyright disclosure or permission is required for the figures (own figures).

\section{Acknowledgments}

We are very grateful to the professors and organizers of ASLER seminary (for Systematic Analysis of the Literature in Rheumatology) for their useful advice in the writing of this manuscript.

\section{Author details}

${ }^{1}$ Département de Rhumatologie, Hôpital Pellegrin, CHU de Bordeaux, Bordeaux, France. 'Laboratoire d'Immunologie, UMR-CNRS 5164, Université de Bordeaux, Bordeaux, France. ${ }^{3}$ Unité sous Contrat, Infections à Mycoplasmes et à Chlamydia chez l'Homme, Université de Bordeaux, Bordeaux, France.

Received: 22 April 2015 Accepted: 18 August 2015

Published online: 04 September 2015

\section{References}

1. Rosenberg SA. Decade in review-cancer immunotherapy: entering the mainstream of cancer treatment. Nat Rev Clin Oncol. 2014;11:630-2.

2. Waldmann TA. Immunotherapy: past, present and future. Nat Med. 2003;9:269-77.

3. Pardoll DM. The blockade of immune checkpoints in cancer immunotherapy. Nat Rev Cancer. 2012;12:252-64

4. O'Day SJ, Hamid O, Urba WJ. Targeting cytotoxic T-lymphocyte antigen-4 (CTLA-4): a novel strategy for the treatment of melanoma and other malignancies. Cancer. 2007;110:2614-27.

5. Tivol EA, Borriello F, Schweitzer AN, Lynch WP, Bluestone JA, Sharpe AH. Loss of CTLA-4 leads to massive lymphoproliferation and fatal multiorgan tissue destruction, revealing a critical negative regulatory role of CTLA-4. Immunity. 1995;3:541-7.

6. Kuehn HS, Ouyang W, Lo B, Deenick EK, Niemela JE, Avery DT, et al. Immune dysregulation in human subjects with heterozygous germline mutations in CTLA4. Science. 2014;345:1623-7.

7. Hodi FS, O'Day SJ, McDermott DF, Weber RW, Sosman JA, Haanen JB, et al. Improved survival with ipilimumab in patients with metastatic melanoma. N Engl J Med. 2010;363:711-23.

8. Robert C, Thomas L, Bondarenko I, O'Day S, JW MD, Garbe C, et al. Ipilimumab plus dacarbazine for previously untreated metastatic melanoma. N Engl J Med. 2011;364:2517-26.

9. Ribas A, Hanson DC, Noe DA, Millham R, Guyot DJ, Bernstein SH, et al. Tremelimumab (CP-675,206), a cytotoxic T lymphocyte associated antigen 4 blocking monoclonal antibody in clinical development for patients with cancer. Oncologist. 2007;12:873-83.

10. Calabrò L, Danielli R, Sigalotti L, Maio M. Clinical studies with anti-CTLA-4 antibodies in non-melanoma indications. Semin Oncol. 2010;37:460-7.

11. Higgins JPT, Altman DG, Gøtzsche PC, Jüni P, Moher D, Oxman AD, et al. The Cochrane Collaboration's tool for assessing risk of bias in randomised trials. BMJ. 2011;343:d5928.

12. Bernardo SG, Moskalenko M, Pan M, Shah S, Sidhu HK, Sicular S, et al. Elevated rates of transaminitis during ipilimumab therapy for metastatic melanoma. Melanoma Res. 2013:23:47-54

13. Carthon BC, Wolchok JD, Yuan J, Kamat A, Ng Tang DS, Sun J, et al. Preoperative CTLA-4 blockade: tolerability and immune monitoring in the setting of a presurgical clinical trial. Clin Cancer Res. 2010;16:2861-71.
14. Wilgenhof S, Du Four S, Vandenbroucke F, Everaert H, Salmon I, Liénard D, et al. Single-center experience with ipilimumab in an expanded access program for patients with pretreated advanced melanoma. J Immunother. 2013:36:215-22.

15. Delyon J, Mateus C, Lefeuvre D, Lanoy E, Zitvogel L, Chaput N, et al. Experience in daily practice with ipilimumab for the treatment of patients with metastatic melanoma: an early increase in lymphocyte and eosinophil counts is associated with improved survival. Ann Oncol. 2013:24:1697-703.

16. Margolin K, Ernstoff MS, Hamid O, Lawrence D, McDermott D, Puzanov I, et al. Ipilimumab in patients with melanoma and brain metastases: an openlabel, phase 2 trial. Lancet Oncol. 2012;13:459-65.

17. Hamid O, Schmidt H, Nissan A, Ridolfi L, Aamdal S, Hansson J, et al. A prospective phase $\|$ trial exploring the association between tumor microenvironment biomarkers and clinical activity of ipilimumab in advanced melanoma. J Transl Med. 2011;9:204

18. Danielli R, Ridolfi R, Chiarion-Sileni V, Queirolo P, Testori A, Plummer R, et al. Ipilimumab in pretreated patients with metastatic uveal melanoma: safety and clinical efficacy. Cancer Immunol Immunother. 2012;61:41-8.

19. Wolchok JD, Neyns B, Linette G, Negrier S, Lutzky J, Thomas L, et al. Ipilimumab monotherapy in patients with pretreated advanced melanoma: a randomised, double-blind, multicentre, phase 2, dose-ranging study. Lancet Oncol. 2010;11:155-64.

20. O'Day SJ, Maio M, Chiarion-Sileni V, Gajewski TF, Pehamberger $\mathrm{H}$, Bondarenko IN, et al. Efficacy and safety of ipilimumab monotherapy in patients with pretreated advanced melanoma: a multicenter single-arm phase II study. Ann Oncol. 2010;21:1712-7.

21. Hersh EM, O'Day SJ, Powderly J, Khan KD, Pavlick AC, Cranmer LD, et al. A phase II multicenter study of ipilimumab with or without dacarbazine in chemotherapy-naïve patients with advanced melanoma. Invest New Drugs. 2011:29:489-98.

22. Weber J, Thompson JA, Hamid O, Minor D, Amin A, Ron I, et al. A randomized, double-blind, placebo-controlled, phase II study comparing the tolerability and efficacy of ipilimumab administered with or without prophylactic budesonide in patients with unresectable stage III or IV melanoma. Clin Cancer Res. 2009;15:5591-8.

23. Yang JC, Hughes M, Kammula U, Royal R, Sherry RM, Topalian SL, et al. Ipilimumab (anti-CTLA4 antibody) causes regression of metastatic renal cell cancer associated with enteritis and hypophysitis. J Immunother. 2007;30:825-30

24. Downey SG, Klapper JA, Smith FO, Yang JC, Sherry RM, Royal RE, et al. Prognostic factors related to clinical response in patients with metastatic melanoma treated by CTL-associated antigen-4 blockade. Clin Cancer Res. 2007:13:6681-8

25. Ku GY, Yuan J, Page DB, Schroeder SEA, Panageas KS, Carvajal RD, et al. Single-institution experience with ipilimumab in advanced melanoma patients in the compassionate use setting: lymphocyte count after 2 doses correlates with survival. Cancer. 2010;116:1767-75.

26. Di Giacomo AM, Danielli R, Calabrò L, Bertocci E, Nannicini C, Giannarelli D, et al. Ipilimumab experience in heavily pretreated patients with melanoma in an expanded access program at the University Hospital of Siena (Italy). Cancer Immunol Immunother. 2011;60:467-77.

27. Royal RE, Levy C, Turner K, Mathur A, Hughes M, Kammula US, et al. Phase 2 trial of single agent Ipilimumab (anti-CTLA-4) for locally advanced or metastatic pancreatic adenocarcinoma. J Immunother. 2010;33:828-33.

28. Le DT, Lutz E, Uram JN, Sugar EA, Onners B, Solt S, et al. Evaluation of ipilimumab in combination with allogeneic pancreatic tumor cells transfected with a GM-CSF gene in previously treated pancreatic cancer. J Immunother. 2013;36:382-9.

29. Weber JS, O'Day S, Urba W, Powderly J, Nichol G, Yellin M, et al. Phase I/II study of ipilimumab for patients with metastatic melanoma. J Clin Oncol. 2008;26:5950-6.

30. Slovin SF, Higano CS, Hamid O, Tejwani S, Harzstark A, Alumkal JJ, et al. Ipilimumab alone or in combination with radiotherapy in metastatic castration-resistant prostate cancer: results from an open-label, multicenter phase I/II study. Ann Oncol. 2013;24:1813-21.

31. Calabrò L, Morra A, Fonsatti E, Cutaia O, Amato G, Giannarelli D, et al. Tremelimumab for patients with chemotherapy-resistant advanced malignant mesothelioma: an open-label, single-arm, phase 2 trial. Lancet Oncol. 2013;14:1104-11.

32. Chung KY, Gore I, Fong L, Venook A, Beck SB, Dorazio P, et al. Phase II study of the anti-cytotoxic T-lymphocyte-associated antigen 4 monoclonal 
antibody, tremelimumab, in patients with refractory metastatic colorectal cancer. J Clin Oncol. 2010;28:3485-90.

33. Ralph C, Elkord E, Burt DJ, O'Dwyer JF, Austin EB, Stern PL, et al. Modulation of lymphocyte regulation for cancer therapy: a phase II trial of tremelimumab in advanced gastric and esophageal adenocarcinoma. Clin Cancer Res. 2010:16:1662-72.

34. Ribas A, Camacho LH, Lopez-Berestein G, Pavlov D, Bulanhagui CA, Millham $\mathrm{R}$, et al. Antitumor activity in melanoma and anti-self responses in a phase I trial with the anti-cytotoxic T lymphocyte-associated antigen 4 monoclonal antibody CP-675,206. J Clin Oncol. 2005:23:8968-77.

35. Ribas A, Kefford R, Marshall MA, Punt CJA, Haanen JB, Marmol M, et al. Phase III randomized clinical trial comparing tremelimumab with standardof-care chemotherapy in patients with advanced melanoma. J Clin Oncol. 2013;31:616-22.

36. Audemard A, de Raucourt S, Miocque S, Comoz F, Giraud JM, Dreno B, et al. Melanoma-associated retinopathy treated with ipilimumab therapy. Dermatology. 2013;227:146-9.

37. Assi H, Wilson KS. Immune toxicities and long remission duration after ipilimumab therapy for metastatic melanoma: two illustrative cases. Curr Oncol Tor Ont. 2013;20:e165-169.

38. Pintova S, Sidhu H, Friedlander PA, Holcombe RF. Sweet's syndrome in a patient with metastatic melanoma after ipilimumab therapy. Melanoma Res. 2013;23:498-501.

39. Blansfield JA, Beck KE, Tran K, Yang JC, Hughes MS, Kammula US, et al. Cytotoxic T-lymphocyte-associated antigen-4 blockage can induce autoimmune hypophysitis in patients with metastatic melanoma and renal cancer. J Immunother. 2005:28:593-8.

40. Kaehler KC, Egberts F, Lorigan P, Hauschild A. Anti-CTLA-4 therapy-related autoimmune hypophysitis in a melanoma patient. Melanoma Res. 2009:19:333-4.

41. Barnard ZR, Walcott BP, Kahle KT, Nahed BV, Coumans JV. Hyponatremia associated with ipilimumab-induced hypophysitis. Med Oncol. 2012;29:3747.

42. Bot I, Blank CU, Boogerd W, Brandsma D. Neurological immune-related adverse events of ipilimumab. Pract Neurol. 2013;13:278-80.

43. Min L, Vaidya A, Becker C. Thyroid autoimmunity and ophthalmopathy related to melanoma biological therapy. Eur J Endocrinol. 2011;164:303-7.

44. Van der Hiel B, Blank CU, Haanen JBAG, Stokkel MPM. Detection of early onset of hypophysitis by (18)F-FDG PET-CT in a patient with advanced stage melanoma treated with ipilimumab. Clin Nucl Med. 2013;38:e182-184.

45. Lammert A, Schneider HJ, Bergmann T, Benck U, Krämer BK, Gärtner R, et al. Hypophysitis caused by ipilimumab in cancer patients: hormone replacement or immunosuppressive therapy. Exp Clin Endocrinol Diabetes. 2013;121:581-7.

46. Anderson L, Bhatia V. Ipilimumab immune-related adverse reactions: a case report. S D Med. 2013;66:315-7.

47. Juszczak A, Gupta A, Karavitaki N, Middleton MR, Grossman AB. Ipilimumab: a novel immunomodulating therapy causing autoimmune hypophysitis: a case report and review. Eur J Endocrinol. 2012;167:1-5.

48. Carpenter KJ, Murtagh RD, Lilienfeld H, Weber J, Murtagh FR. Ipilimumabinduced hypophysitis: MR imaging findings. AJNR Am J Neuroradiol. 2009;30:1751-3.

49. Minor DR, Bunker SR, Doyle J. Lymphocytic vasculitis of the uterus in a patient with melanoma receiving ipilimumab. J Clin Oncol. 2013;31, e356.

50. Shaw SA, Camacho LH, McCutcheon IE, Waguespack SG. Transient hypophysitis after cytotoxic T lymphocyte-associated antigen 4 (CTLA4) blockade. J Clin Endocrinol Metab. 2007:92:1201-2.

51. Min L, Vaidya A, Becker C. Association of ipilimumab therapy for advanced melanoma with secondary adrenal insufficiency: a case series. Endocr Pract. 2012;18:351-5

52. Harmankaya K, Erasim C, Koelblinger C, Ibrahim R, Hoos A, Pehamberger $H$, et al. Continuous systemic corticosteroids do not affect the ongoing regression of metastatic melanoma for more than two years following ipilimumab therapy. Med Oncol. 2011;28:1140-4.

53. Ledezma B, Binder S, Hamid O. Atypical clinical response patterns to ipilimumab. Clin J Oncol Nurs. 2011;15:393-403.

54. Mitchell KA, Kluger $H$, Sznol M, Hartman DJ. Ipilimumab-induced perforating colitis. J Clin Gastroenterol. 2013;47:781-5.

55. Lord JD, Hackman RC, Moklebust A, Thompson JA, Higano CS, Chielens D, et al. Refractory colitis following anti-CTLA4 antibody therapy: analysis of mucosal FOXP3+ T cells. Dig Dis Sci. 2010;55:1396-405.
56. Koch C, Paetzold S, Trojan J. Enterocolitis in a patient being treated with ipilimumab for metastatic melanoma. Gastroenterology. 2012;143:298, 504, 505.

57. Minor DR, Chin K, Kashani-Sabet M. Infliximab in the treatment of antiCTLA4 antibody (ipilimumab) induced immune-related colitis. Cancer Biother Radiopharm. 2009;24:321-5.

58. Slingerland M, Nortier JWR, Veenendaal RA, Kapiteijn E. Severe colitis while responding to ipilimumab in metastatic melanoma. Acta Oncol. 2012;51:805-7.

59. García-Varona A, Odze RD, Makrauer F. Lymphocytic colitis secondary to ipilimumab treatment. Inflamm Bowel Dis. 2013;19:E15-16.

60. Lyall A, Vargas HA, Carvajal RD, Ulaner G. Ipilimumab-induced colitis on FDG PET/CT. Clin Nucl Med. 2012;37:629-30.

61. Tsiaras A. Case of the month. Autoimmune colitis secondary to CTLA-4 blockade. JAAPA. 2011;24:68.

62. Pagès C, Gornet JM, Monsel G, Allez M, Bertheau P, Bagot M, et al. Ipilimumab-induced acute severe colitis treated by infliximab. Melanoma Res. 2013;23:227-30.

63. Kim KW, Ramaiya NH, Krajewski KM, Shinagare AB, Howard SA, Jagannathan $J P$, et al. Ipilimumab-associated colitis: $C T$ findings. Am J Roentgenol. 2013:200:W468-474

64. Kleiner DE, Berman D. Pathologic changes in ipilimumab-related hepatitis in patients with metastatic melanoma. Dig Dis Sci. 2012;57:2233-40.

65. Chmiel KD, Suan D, Liddle C, Nankivell B, Ibrahim R, Bautista C, et al. Resolution of severe ipilimumab-induced hepatitis after antithymocyte globulin therapy. J Clin Oncol. 2011;29:e237-240.

66. Di Giacomo AM, Danielli R, Guidoboni M, Calabrò L, Carlucci D, Miracco C, et al. Therapeutic efficacy of ipilimumab, an anti-CTLA-4 monoclonal antibody, in patients with metastatic melanoma unresponsive to prior systemic treatments: clinical and immunological evidence from three patient cases. Cancer Immunol Immunother. 2009;58:1297-306.

67. Gentile NM, D'Souza A, Fujii LL, Wu T-T, Murray JA. Association between ipilimumab and celiac disease. Mayo Clin Proc. 2013;88:414-7.

68. Wilgenhof S, Neyns B. Anti-CTLA-4 antibody-induced Guillain-Barré syndrome in a melanoma patient. Ann Oncol. 2011;22:991-3.

69. Gaudy-Marqueste C, Monestier S, Franques J, Cantais E, Richard M-A, Grob JJ. A severe case of ipilimumab-induced Guillain-Barré syndrome revealed by an occlusive enteric neuropathy: a differential diagnosis for ipilimumabinduced colitis. J Immunother. 2013;36:77-8.

70. Liao B, Shroff S, Kamiya-Matsuoka C, Tummala S. Atypical neurological complications of ipilimumab therapy in patients with metastatic melanoma. Neuro Oncol. 2014;16:589-93.

71. Hunter G, Voll C, Robinson CA. Autoimmune inflammatory myopathy after treatment with ipilimumab. Can J Neurol Sci. 2009;36:518-20.

72. Lecouflet M, Verschoore M, Giard C, Gohier P, Le Corre Y, Milea D, et al. Orbital myositis associated with ipilimumab. Ann Dermatol Vénéréologie. 2013:140:448-51.

73. Bhatia S, Huber BR, Upton MP, Thompson JA. Inflammatory enteric neuropathy with severe constipation after ipilimumab treatment for melanoma: a case report. J Immunother. 2009;32:203-5.

74. Maur M, Tomasello C, Frassoldati A, Dieci MV, Barbieri E, Conte P. Posterior reversible encephalopathy syndrome during ipilimumab therapy for malignant melanoma. J Clin Oncol. 2012;30:e76-78.

75. Manousakis G, Koch J, Sommerville RB, El-Dokla A, Harms MB, Al-Lozi MT, et al. Multifocal radiculoneuropathy during ipilimumab treatment of melanoma. Muscle Nerve. 2013;48:440-4.

76. Bompaire F, Mateus C, Taillia H, De Greslan T, Lahutte M, SallansonnetFroment $\mathrm{M}$, et al. Severe meningo-radiculo-neuritis associated with ipilimumab. Invest New Drugs. 2012;30:2407-10.

77. Gilardi L, Colandrea M, Vassallo S, Travaini LL, Paganelli G. Ipilimumabinduced immunomediated adverse events: possible pitfalls in (18)F-FDG PET/CT interpretation. Clin Nucl Med. 2013;39:472-4.

78. Reule RB, North JP. Cutaneous and pulmonary sarcoidosis-like reaction associated with ipilimumab. J Am Acad Dermatol. 2013;69:e272-273.

79. Berthod G, Lazor R, Letovanec I, Romano E, Noirez L, Mazza Stalder J, et al. Pulmonary sarcoid-like granulomatosis induced by ipilimumab. J Clin Oncol. 2012;30:e156-159.

80. Tissot C, Carsin A, Freymond N, Pacheco Y, Devouassoux G. Sarcoidosis complicating anti-cytotoxic T-lymphocyte-associated antigen-4 monoclonal antibody biotherapy. Eur Respir J. 2013:41:246-7.

81. Vogel WV, Guislain A, Kvistborg P, Schumacher TNM, Haanen JBAG, Blank CU. Ipilimumab-induced sarcoidosis in a patient with metastatic melanoma undergoing complete remission. J Clin Oncol. 2012;30:e7-e10. 
82. Eckert A, Schoeffler A, Dalle S, Phan A, Kiakouama L, Thomas L. Anti-CTLA4 monoclonal antibody induced sarcoidosis in a metastatic melanoma patient. Dermatololy. 2009;218:69-70.

83. Sun J, Schiffman J, Raghunath A, Ng Tang D, Chen H, Sharma P. Concurrent decrease in IL-10 with development of immune-related adverse events in a patient treated with anti-CTLA-4 therapy. Cancer Immun. 2008:8:9.

84. Barjaktarevic IZ, Qadir N, Suri A, Santamauro JT, Stover D. Organizing pneumonia as a side effect of ipilimumab treatment of melanoma. Chest. 2013;143:858-61.

85. Fadel F, El Karoui K, Knebelmann B. Anti-CTLA4 antibody-induced lupus nephritis. N Engl J Med. 2009;361:211-2.

86. Gordon IO, Wade T, Chin K, Dickstein J, Gajewski TF. Immune-mediated red cell aplasia after anti-CTLA-4 immunotherapy for metastatic melanoma. Cancer Immunol Immunother. 2009;58:1351-3.

87. Akhtari M, Waller EK, Jaye DL, Lawson DH, Ibrahim R, Papadopoulos NE, et al. Neutropenia in a patient treated with ipilimumab (anti-CTLA-4 antibody). J Immunother. 2009:32:322-4

88. Ahmad S, Lewis M, Corrie P, Iddawela M. Ipilimumab-induced thrombocytopenia in a patient with metastatic melanoma. J Oncol Pharm Pract. 2012;18:287-92.

89. Delyon J, Mateus C, Lambert T. Hemophilia A induced by ipilimumab. N Engl J Med. 2011;365:1747-8.

90. Goldstein BL, Gedmintas L, Todd DJ. Drug-associated polymyalgia rheumatica/giant cell arteritis occurring in two patients after treatment with ipilimumab, an antagonist of CTLA-4. Arthritis Rheumatol. 2014;66:768-9.

91. Forde PM, Rock K, Wilson G, O'Byrne KJ. Ipilimumab-induced immunerelated renal failure - a case report. Anticancer Res. 2012;32:4607-8.

92. Jaber SH, Cowen EW, Haworth LR, Booher SL, Berman DM, Rosenberg SA, et al. Skin reactions in a subset of patients with stage IV melanoma treated with anti-cytotoxic T-lymphocyte antigen 4 monoclonal antibody as a single agent. Arch Dermatol. 2006;142:166-72.

93. Minkis K, Garden BC, Wu S, Pulitzer MP, Lacouture ME. The risk of rash associated with ipilimumab in patients with cancer: a systematic review of the literature and meta-analysis. J Am Acad Dermatol. 2013;69:e121-128.

94. Salenave J, Chanson P, Young J. Hypophysite lymphocytaire. Endocrinologie-Nutrition, 10-023-D-10. Paris: Elsevier Masson SAS; 2007.

95. Beck KE, Blansfield JA, Tran KQ, Feldman AL, Hughes MS, Royal RE, et al. Enterocolitis in patients with cancer after antibody blockade of cytotoxic Tlymphocyte-associated antigen 4. J Clin Oncol. 2006;24:2283-9.

96. Ibrahim R, Berman DM, DePril V, Humphrey T, Chen M, Messina M, et al. Ipilimumab safety profile: summary of findings from completed trials in advanced melanoma. J Clin Oncol. 2011;29:abstract 8583.

97. Voskens CJ, Goldinger SM, Loquai C, Robert C, Kaehler KC, Berking C, et al. The price of tumor control: an analysis of rare side effects of anti-CTLA-4 therapy in metastatic melanoma from the ipilimumab network. PLoS One. 2013;8, e53745.

98. Teply BA, Lipson EJ. Identification and management of toxicities from immune checkpoint-blocking drugs. Oncology (Williston Park). 2014;28:30-8.

99. McDermott D, Haanen J, Chen T-T, Lorigan P, O'Day S. MDX010-20 Investigators. Efficacy and safety of ipilimumab in metastatic melanoma patients surviving more than 2 years following treatment in a phase III trial (MDX010-20). Ann Oncol. 2013;24:2694-8.

100. Lebbé C, Weber JS, Maio M, Neyns B, Harmankaya K, Hamid O, et al. Survival follow-up and ipilimumab retreatment of patients with advanced melanoma who received ipilimumab in prior phase $\|$ studies. Ann Oncol. 2014;25:2277-84

101. Chiarion-Sileni V, Pigozzo J, Ascierto PA, Simeone E, Maio M, Calabrò L, et al. Ipilimumab retreatment in patients with pretreated advanced melanoma: the expanded access programme in Italy. Br J Cancer. 2014;110:1721-6.

102. Robert C, Schadendorf D, Messina M, Hodi FS, O'Day S. MDX010-20 investigators. Efficacy and safety of retreatment with ipilimumab in patients with pretreated advanced melanoma who progressed after initially achieving disease control. Clin Cancer Res. 2013;19:2232-9.

103. Albarel F, Gaudy C, Castinetti F, Carré T, Morange I, Conte-Devolx B, et al. Long-term follow-up of ipilimumab-induced hypophysitis, a common adverse event of the anti-CTLA-4 antibody in melanoma. Eur J Endocrinol. 2015;172:195-204.

104. Attia P, Phan GQ, Maker AV, Robinson MR, Quezado MM, Yang JC, et al. Autoimmunity correlates with tumor regression in patients with metastatic melanoma treated with anti-cytotoxic T-lymphocyte antigen-4. J Clin Oncol. 2005;23:6043-53.
105. Bouwhuis MG, Ten Hagen TLM, Suciu S, Eggermont AM. Autoimmunity and treatment outcome in melanoma. Curr Opin Oncol. 2011:23:170-6.

106. McCoy KD, Le Gros G. The role of CTLA-4 in the regulation of T cell immune responses. Immunol Cell Biol. 1999;77:1-10.

107. Bour-Jordan H, Bluestone JA. Regulating the regulators: costimulatory signals control the homeostasis and function of regulatory T cells. Immunol Rev. 2009;229:41-66.

108. Simpson TR, Li F, Montalvo-Ortiz W, Sepulveda MA, Bergerhoff K, Arce F, et al. Fc-dependent depletion of tumor-infiltrating regulatory $T$ cells co-defines the efficacy of anti-CTLA-4 therapy against melanoma. J Exp Med. 2013;210:1695-710

109. Picchianti Diamanti A, Rosado MM, Scarsella M, Germano V, Giorda E, Cascioli S, et al. Abatacept (cytotoxic T lymphocyte antigen 4immunoglobulin) improves B cell function and regulatory $T$ cell inhibitory capacity in rheumatoid arthritis patients non-responding to anti-tumour necrosis factor-a agents. Clin Exp Immunol. 2014;177:630-40.

110. Lee YK, Mazmanian SK. Has the microbiota played a critical role in the evolution of the adaptive immune system? Science. 2010;330:1768-73.

111. Kyi C, Carvajal RD, Wolchok JD, Postow MA. Ipilimumab in patients with melanoma and autoimmune disease. J Immunother Cancer. 2014;2:35.

112. Pedersen $M$, Andersen $R$, Nørgaard $P$, Jacobsen $S$, Thielsen $P$, Thor Straten $P$, et al. Successful treatment with ipilimumab and interleukin-2 in two patients with metastatic melanoma and systemic autoimmune disease. Cancer Immunol Immunother. 2014;63:1341-6.

113. Lipson EJ, Bodell MA, Kraus ES, Sharfman WH. Successful administration of ipilimumab to two kidney transplantation patients with metastatic melanoma. J Clin Oncol. 2014;32:e69-71.

114. Bristol-Myers Squibb. YERVOY (ipilimumab): immune-mediated adverse reaction management guide. 2011. https://www.hcp.yervoy.com/pdf/ 731US15BR00848-01-01_DIGITAL\%20_YERVOY\%20AR\%20Management\% 20Guide_AFP_7\%208\%2015_CMKY.pdf

115. Tarhini A. Immune-mediated adverse events associated with ipilimumab ctla-4 blockade therapy: the underlying mechanisms and clinical management. Scientifica. 2013;2013:857519.

116. Lacouture ME, Wolchok JD, Yosipovitch G, Kähler KC, Busam KJ, Hauschild A. Ipilimumab in patients with cancer and the management of dermatologic adverse events. J Am Acad Dermatol. 2014;71:161-9.

117. Queirolo P, Morabito A, Laurent S, Lastraioli S, Piccioli P, Ascierto PA, et al. Association of CTLA-4 polymorphisms with improved overall survival in melanoma patients treated with CTLA-4 blockade: a pilot study. Cancer Invest. 2013;31:336-45.

118. Breunis WB, Tarazona-Santos E, Chen R, Kiley M, Rosenberg SA, Chanock SJ. Influence of cytotoxic T lymphocyte-associated antigen 4 (CTLA4) common polymorphisms on outcome in treatment of melanoma patients with CTLA-4 blockade. J Immunother. 2008;31:586-90.

119. Snyder A, Makarov V, Merghoub T, Yuan J, Zaretsky JM, Desrichard A, et al. Genetic basis for clinical response to CTLA-4 blockade in melanoma. N Engl J Med. 2014;371:2189-99.

120. Di Giacomo AM, Calabrò L, Danielli R, Fonsatti E, Bertocci E, Pesce I, et al. Long-term survival and immunological parameters in metastatic melanoma patients who responded to ipilimumab $10 \mathrm{mg} / \mathrm{kg}$ within an expanded access programme. Cancer Immunol Immunother. 2013;62:1021-8

121. Vudattu NK, Waldron-Lynch F, Truman LA, Deng S, Preston-Hurlburt $P$, Torres $\mathrm{R}$, et al. Humanized mice as a model for aberrant responses in human T cell immunotherapy. J Immunol. 2014;193:587-96.

122. Simeone E, Grimaldi AM, Esposito A, Curvietto M, Palla M, Paone M, et al. Serious haematological toxicity during and after ipilimumab treatment: a case series. J Med Case Reports. 2014;8:240.

123. Du Rusquec P, Saint-Jean M, Brocard A, Peuvrel L, Khammari A, Quéreux G, et al. Ipilimumab-induced autoimmune pancytopenia in a case of metastatic melanoma. J Immunother. 2014;37:348-50.

124. Izzedine H, Gueutin V, Gharbi C, Mateus C, Robert C, Routier E, et al. Kidney injuries related to ipilimumab. Invest New Drugs. 2014;32:769-73.

125. Munoz J, Guillot B, Girard C, Dereure O, Du-Thanh A. First report of ipilimumab-induced Grover disease. Br J Dermatol. 2014;171(5):1236-7.

126. Kyllo RL, Parker MK, Rosman I, Musiek AC. Ipilimumab-associated Sweet syndrome in a patient with high-risk melanoma. J Am Acad Dermatol. 2014; $70: e 85-86$

127. Sheik Ali S, Goddard AL, Luke JJ, Donahue H, Todd DJ, Werchniak A, et al. Drug-associated dermatomyositis following ipilimumab therapy: a novel 
immune-mediated adverse event associated with cytotoxic T-lymphocyte antigen 4 blockade. JAMA Dermatol. 2015;151(2):195-9.

128. Rudolph BM, Staib F, Von Stebut E, Hainz M, Grabbe S, Loquai C. Neutrophilic disease of the skin and intestines after ipilimumab treatment for malignant melanoma - simultaneous occurrence of pyoderma gangrenosum and colitis. Eur J Dermatol. 2014;24:268-9.

129. McElnea E, Ní Mhéalóid A, Moran S, Kelly R, Fulcher T. Thyroid-like ophthalmopathy in a euthyroid patient receiving ipilimumab. Orbit Amst Neth. 2014;33:424-7.

130. Henderson AD, Thomas DA. A case report of orbital inflammatory syndrome secondary to ipilimumab. Ophthal Plast Reconstr Surg. 2015;31(3):e68-70.

131. Borodic GE, Hinkle D. Ipilimumab-induced orbital inflammation resembling Graves disease with subsequent development of systemic hyperthyroidism from CTLA-4 receptor suppression. Ophthal Plast Reconstr Surg. 2014;30:83.

132. Nallapaneni NN, Mourya R, Bhatt VR, Malhotra S, Ganti AK, Tendulkar KK. Ipilimumab-induced hypophysitis and uveitis in a patient with metastatic melanoma and a history of ipilimumab-induced skin rash. J Natl Compr Cancer Netw. 2014;12:1077-81.

133. Johnson DB, Saranga-Perry V, Lavin PJM, Burnette WB, Clark SW, Uskavitch $\mathrm{DR}$, et al. Myasthenia gravis induced by ipilimumab in patients with metastatic melanoma. J Clin Oncol. 2014. Ahead of print.

134. Luke JJ, Lezcano C, Hodi FS, Murphy GF. Antitumor granuloma formation by CD4+ T cells in a patient with rapidly progressive melanoma experiencing spiking fevers, neuropathy, and other immune-related toxicity after treatment with ipilimumab. J Clin Oncol. 2015;33(6):e32-5

135. Chodakiewitz Y, Brown S, Boxerman JL, Brody JM, Rogg JM. Ipilimumab treatment associated pituitary hypophysitis: clinical presentation and imaging diagnosis. Clin Neurol Neurosurg. 2014;125:125-30.

136. Faje AT, Sullivan R, Lawrence D, Tritos NA, Fadden R, Klibanski A, et al. Ipilimumab-induced hypophysitis: a detailed longitudinal analysis in a large cohort of patients with metastatic melanoma. J Clin Endocrinol Metab. 2014;99:4078-85.

137. Marlier J, Cocquyt V, Brochez L, Van Belle S, Kruse V. Ipilimumab, not just another anti-cancer therapy: hypophysitis as side effect illustrated by four case-reports. Endocrine. 2014:47(3):878-83.

138. Dilling P, Walczak J, Pikiel P, Kruszewski WJ. Multiple colon perforation as a fatal complication during treatment of metastatic melanoma with ipilimumab - case report. Pol Przegl Chir. 2014;86:94-6.

139. Raad RA, Pavlick A, Kannan R, Friedman KP. Ipilimumab-induced hepatitis on 18F-FDG PET/CT in a patient with malignant melanoma. Clin Nucl Med. 2015:40(3):258-9.

140. Murphy KP, Kennedy MP, Barry JE, O’Regan KN, Power DG. New-onset mediastinal and central nervous system sarcoidosis in a patient with metastatic melanoma undergoing CTLA4 monoclonal antibody treatment. Oncol Res Treat. 2014;37:351-3.

\section{Submit your next manuscript to BioMed Central and take full advantage of:}

- Convenient online submission

- Thorough peer review

- No space constraints or color figure charges

- Immediate publication on acceptance

- Inclusion in PubMed, CAS, Scopus and Google Scholar

- Research which is freely available for redistribution

Submit your manuscript at www.biomedcentral.com/submit 